\title{
A Comparative Study of Platelet-rich Fibrin (PRF) and Titanium-prepared Platelet-rich Fibrin (T-PRF) in Management of Endo-perio Lesions
}

\author{
Mohammed A Razi ${ }^{1}$, Ankit Mahajan², Seema Qamar ${ }^{3}$, Salil Mehra ${ }^{4}$, Tulika Rani Roy ${ }^{5}$, Puja Kumari ${ }^{6}$
}

\begin{abstract}
Aim: The aim of the study was to compare the platelet-rich fibrin (PRF) and titanium-prepared platelet-rich fibrin (T-PRF) in the management of endo-perio lesions.

Materials and methods: This study was conducted with 140 patients who are affected by endo-perio lesions, and the patients were divided into two groups. In group I, patients were treated with PRF, and in group II, patients were treated with T-PRF. Endodontic treatment was done in all cases, following a standardized aseptic method. Probing pocket and relative attachment level were recorded after 3 months and 6 months in both groups.

Results: After 3 months, the mean change of probing pocket depth (PPD) was $68 \%$ in group I and $33.41 \%$ in group II. The intergroup distinction was not significant $(p>0.05)$, whereas the intragroup evaluation was significant $(p<0.05)$. The mean change after 6 months was $42.59 \%$ in group I and $43.90 \%$ in group II. The difference was not significant $(p>0.05)$. After 3 months, the mean\% change of relative attachment level (RAL) was $31.20 \%$ in group I and $31.60 \%$ in group II. The intergroup distinction was not significant $(p>0.05)$, whereas the intragroup evaluation established a considerable discrepancy $(p<0.05)$. The mean change after 6 months was $40.82 \%$ in group I and $42.12 \%$ in group II.

Conclusion: Both PRF and T-PRF were effective in inducing a reduction in pocket depth and useful in gaining attachment level.

Clinical significance: With the use of PRF and T-PRF, the complex case of endo-perio lesions can be efficiently managed.

Keywords: Endo-perio lesions, Platelet-rich fibrin, Titanium-prepared platelet-rich fibrin.

The Journal of Contemporary Dental Practice (2020): 10.5005/jp-journals-10024-2865
\end{abstract}

\section{INTRODUCTION}

The dental pulp and the periodontium are ectomesenchymal in origin; periodontal ligament originates from the dental follicle and the pulp from the dental papilla. There is a direct communication between the both through dentinal tubules, lateral and accessory canals, and apical foramen. In the disease process, it can correspond through deep periodontal pockets, developmental grooves, and dentinal tubules. ${ }^{1}$ Thus, there is a transfer of disease process from pulp to the periodontium. Numerous microorganisms are responsible for this infection.

Combined endo-perio lesions are difficult to treat, and those are a challenge for clinicians. Mostly, multi-rooted teeth are prone to involve and they have a poor prognosis. There is a need to treat both the root canal and periodontal tissues. ${ }^{2}$ The success rate of conventional root canal therapy is relatively higher in the absence of any periodontal involvement, whereas it is comparatively low in endo-periocases, especially when regenerative measures are not performed. For the successful management of cases, correct diagnosis is essential. The history of clinical examination along with radiographic evaluation ensures better results. ${ }^{3}$

Concurrent occurrence of pulpal and periodontal diseases can obscure diagnosis and treatment planning. In such cases, the vitality test may not indicate the histological condition of the dental pulp. Occasionally chronic inflammatory reaction of the infected root canal can expand into the gingival sulcus and drain through the sinus tracts. The periodontal manifestation tends to heal soon after endodontic treatment if there are no local periodontal factors. The management of endo-perio lesions is not unidirectional but contains a variety of treatment decisions that will result in optimum

\begin{abstract}
1,6Department of Periodontology, Hazaribag College of Dental Sciences and Hospital, Hazaribag, Jharkhand, India

${ }^{2}$ Department of Periodontology, Government Dental College, Shimla, Himachal Pradesh, India

${ }^{3}$ Department of Pediatric and Preventive Dentistry, Hazaribag College of Dental Sciences and Hospital, Hazaribag, Jharkhand, India

${ }^{4}$ Department of Conservative and Endodontic Dentistry, Government Dental College, Shimla, Himachal Pradesh, India

${ }^{5}$ Department of Periodontology, Career Post Graduate Institute of Dental Sciences and Hospital, Lucknow, Uttar Pradesh, India
\end{abstract}

Corresponding Author: Mohammed A Razi, Department of Periodontology, Hazaribag College of Dental Sciences and Hospital, Hazaribag, Jharkhand, India, e-mail: mahsan0708@gmail.com

How to cite this article: Razi MA, Mahajan A, Qamar S, et al. A Comparative Study of Platelet-rich Fibrin (PRF) and Titaniumprepared Platelet-rich Fibrin (T-PRF) in Management of Endo-perio Lesions. J Contemp Dent Pract 2020;21(9):997-1001.

Source of support: Nil

Conflict of interest: None

resolution of the disease process. ${ }^{4}$ For the management of the cases of endo-perio lesions, numerous treatment modalities have been studied. ${ }^{5,6}$

Researchers have done studies utilizing treatment using open flap debridement, root resection, and retrograde filling. Recent strategies involve regenerative procedures such as guided tissue regeneration (GTR), bone grafts, and growth factors. Platelet-rich plasma (PRP) is considered a second-generation platelet derivative. 
The PRP is an autologous fibrin matrix contains a large number of platelets. ${ }^{5,6}$ They have a potential role in wound healing. Platelet-rich fibrin (PRF) enriched with platelets and growth factors encourages periapical tissue regeneration and healing. Titanium-prepared platelet-rich fibrin (T-PRF) is a platelet and leukocyte-rich fibrin similar to that obtained from classical PRF method. ${ }^{7}$ Titanium has corrosion resistance and highest strength-to-weight ratios among metals. It has outstanding biocompatibility due to the noncorrosive nature. The titanium also demonstrates an exceptional property of osseointegration. ${ }^{5}$ With the available background information, the present study was conducted to compare PRF and T-PRF in the management of endo-perio lesions.

\section{Materials and Methods}

This study was done in the Department of Periodontology, Hazaribag College of Dental Sciences and Hospital, Hazaribag, after obtaining the approval from the Institutional Ethics Committee.

This study comprises 140 patients in the age group of 18-58 years of both genders. Assuming $(p)=90$ as the incidence of disease with $9 \%$ margin of error, the formula used was $n=\frac{Z_{\alpha / 2}^{2} p q}{d^{2}}$ where $p$ is the incidence of disease, $q=1-p, d$ is the margin of error, and $Z_{\alpha / 2}$ is the ordinate of standard normal allocation at $\alpha \%$ level of implication. Thus, a sample size of 140 patients was included in the study.

All patients with endo-perio lesions (primary endo and secondary perio) in multi-rooted mandibular teeth, with no history of antibiotics in the last 3 months, and systemically healthy patients were included. The patients on antibiotics, patients with recent endodontics or periodontal surgery, smokers, pregnant or lactating mothers, and those not giving consent were excluded. ${ }^{6}$ Endo-perio lesions are commonly seen in premolars and molars; hence, mandibular molars were chosen for the study. All enrolled patients were informed regarding the study, and written consent was obtained in vernacular language. This double-blind study was done by two trained investigators to avoid bias in the result. The average of two investigators was taken for statistical consideration.

Patients were divided into two groups. In group I, patients with the PRF were used, and in group II, patients with T-PRF were used. All the patients had undergone endodontic treatment with standardized aseptic procedures by two endodontists. Endodontic treatment was completed for all the teeth involved before the periodontal procedure.

The PRF was prepared by aspirating $10 \mathrm{~mL}$ of blood from the antecubital vein in a plain vacutainer tube and the sample was immediately centrifuged at 3,000 rpm for 10 minutes, at room temperature in a tabletop centrifuge. The titanium tubes were used to obtain T-PRF at $2800 \mathrm{rpm}$ for 12 minutes to prepare fibrin-PRF using the same procedure.

The defect was thoroughly evaluated. In group I cases, the PRF was utilized, and in group II cases, the T-PRF was utilized to fill the defect followed by suturing. Coe-Pack was placed. Postoperative instructions were given to all the patients. Amoxicillin $500 \mathrm{mg}$, Metronidazole $400 \mathrm{mg}$, analgesics diclofenac sodium, and $0.2 \%$ chlorhexidine mouthwash were prescribed twice daily for two weeks. Infrabony defect (one-, two-, and three-wall defects) was measured on the digital radiographs taken with the grid. Probing pocket depth $(\mathrm{mm})$ and attachment level $(\mathrm{RAL})(\mathrm{mm})$ were recorded after 3 months and 6 months.

\section{Statistical Analysis}

The results thus obtained were analyzed statistically using SPSS version 21.0 (IBM. Chicago, USA) and unpaired $t$ test. The level of implication was set less than 0.05 .

\section{Results}

Table 1 shows that the age group 18-28 comprised of 16 (20\%) males and 20 (33.3\%) females, 29-38 had 18 (22.5\%) males and 14 (23.3\%) females, 39-48 years had 26 (32.5\%) males and $14(23.3 \%)$ females, and 49-58 years had 20 (25\%) males and 12 (20\%) females. There was no statistically significant difference between the male and female groups of the participants. The percentage of success was higher at age groups $18-28$ and $29-38$. In the present study, 78 (55.7\%) cases had two-wall defects and 62 (44.3\%) cases had three-wall defects.

After 3 months, the mean change of probing pocket depth (PPD) was $2.10 \mathrm{~mm}(32.68 \%)$ in group I and $1.91 \mathrm{~mm}(33.41 \%)$ in group II. The results are shown in Table 2 and Figure 1. There was non-significant difference in intergroup dissimilarity $(p>0.05)$ whereas intragroup comparison showed a significant difference $(p<0.05)$. The mean change after 6 months was $2.56 \mathrm{~mm}(42.59 \%)$ in group I and $2.51 \mathrm{~mm}(43.90 \%)$ in group II. The results were not significant $(p>0.05)$.

Table 3 and Figure 2 show that after 3 months, a mean change of relative attachment level (RAL) was $1.92 \mathrm{~mm}$ (31.20\%) in group I and $1.81 \mathrm{~mm}(31.60 \%)$ in group II. The intergroup distinction was nonsignificant $(p>0.05)$, whereas intragroup evaluation established considerable discrepancy $(p<0.05)$. The mean change after 6 months was $2.52 \mathrm{~mm}(40.82 \%)$ in group I and $2.41 \mathrm{~mm}(42.12 \%)$ in group II. The dissimilarity was not significant $(p>0.05)$.

\section{Discussion}

The occurrence of endo-perio lesions especially in multi-rooted teeth is not uncommon. ${ }^{8}$ Research has delineated that the use of biomaterials in association with bone graft substitutes is found to be a competent treatment method in treating infrabony defects and grade Il furcation defects. Though there are numerous regenerative materials available, none is regarded as the gold standard in the treatment of Grade II furcation defects. ${ }^{9}$

The preparation of PRF is a simple and efficient technique. It is available through autologous blood. ${ }^{10}$ It will accelerate the healing rate of the grafted bone. In the preparation, minimal blood manipulation is needed. The advantage of PRF is that it can be used exclusively or in combination with other grafts. It is economical in comparison with the other bone grafts. The natural fibrin framework with growth factors within imparts prolonged activity that stimulates tissue regeneration effectively. ${ }^{11}$ This study compared the clinical outcome of PRF and T-PRF in the management of endo-perio lesions.

Table 1: Distribution of patients

\begin{tabular}{lll}
\hline Age groups (years) & Male & Female \\
\hline $18-28$ & $16(20 \%)$ & $20(33.3 \%)$ \\
$29-38$ & $18(22.5 \%)$ & $14(23.3 \%)$ \\
$39-48$ & $26(32.5 \%)$ & $14(23.3 \%)$ \\
$49-58$ & $20(25 \%)$ & $12(20 \%)$ \\
Total & 80 & 60 \\
\hline
\end{tabular}


Table 2: Probing pocket depth $(\mathrm{mm})$ in both groups

\begin{tabular}{|c|c|c|c|c|c|c|}
\hline \multirow[b]{2}{*}{ Period } & \multicolumn{2}{|c|}{ Group I } & \multicolumn{2}{|c|}{ Group II } & \multirow[b]{2}{*}{$t$ test } & \multirow[b]{2}{*}{$p$ value } \\
\hline & Mean change & $\%$ change & Mean change & $\%$ change & & \\
\hline 3 months & 2.10 & 32.68 & 1.91 & 33.41 & 0.172 & 0.912 \\
\hline 6 months & 2.56 & 42.59 & 2.51 & 43.90 & 0.235 & 0.891 \\
\hline
\end{tabular}

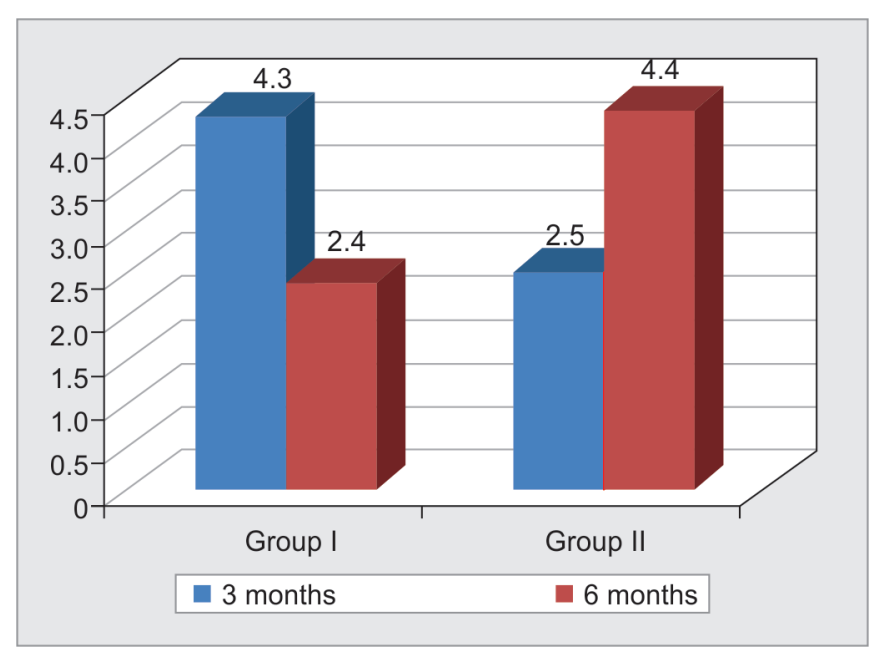

Fig. 1: Percentage change of probing pocket depth in both groups

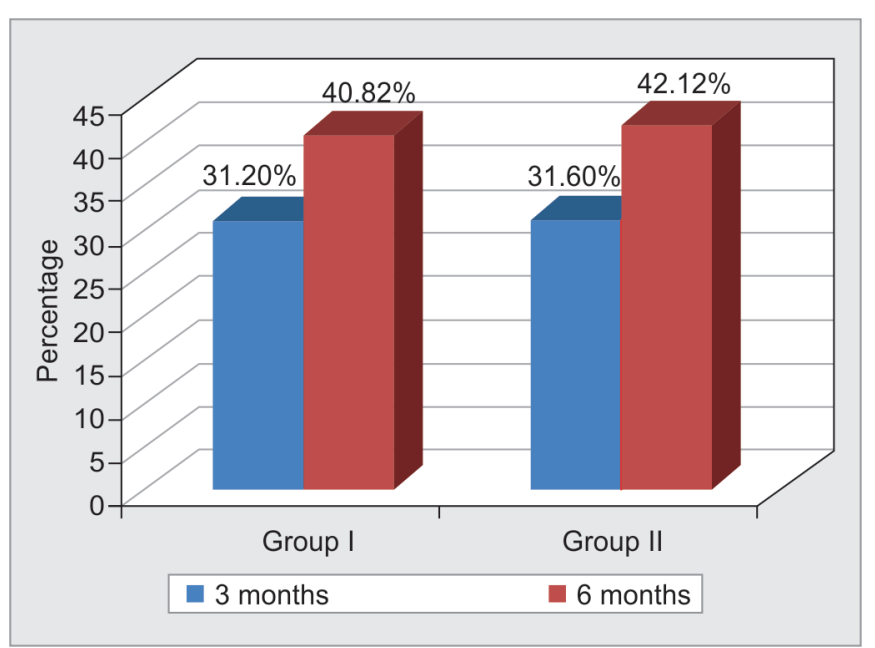

Fig. 2: Percentage change of relative attachment level in both groups

Table 3: Relative attachment level $(\mathrm{mm})$ in both groups

\begin{tabular}{|c|c|c|c|c|c|c|}
\hline \multirow[b]{2}{*}{ Period } & \multicolumn{2}{|c|}{ Group I } & \multicolumn{2}{|c|}{ Group II } & \multirow[b]{2}{*}{ t test } & \multirow[b]{2}{*}{$p$ value } \\
\hline & Mean change & $\%$ change & Mean change & $\%$ change & & \\
\hline 3 months & 1.92 & 31.20 & 1.81 & 31.60 & 0.174 & 0.871 \\
\hline 6 months & 2.52 & 40.82 & 2.41 & 42.12 & 0.178 & 0.878 \\
\hline
\end{tabular}

Alveolar bone loss is one of the most significant aspects of periodontal disease. Periodontal disease is described by the periods of disease bustle, in which dental support structures are destroyed by the action of chemical mediators of inflammation followed by attachment loss, and alveolar bone loss. The current methods for diagnosis of periodontal disease include probing of gingival tissues and radiographs. Periodontal bone loss can be either horizontal or vertical. Bone defects can be crater-like, one-wall, two-wall, three-wall defects, or a combination. There are few studies carried out in the prevalence and distribution of infrabony defects. ${ }^{12,13}$

Singh et al. evaluated the prevalence of bone defects with chronic periodontitis with 200 sample sizes and found the following results: 37 (36.6\%) patients had craters and 4 (4\%), one-wall defects, in the age group of 30-40 years; 7 (6.9\%), two-wall defects; 19 (18.8\%), three-wall defects, in the age group of $41-50$ years; $5(9.3 \%)$, craters, 1 (1.9\%), two-wall defects; and 8 (14.8\%), three-wall defects. In the age group of 51-70, $3(6.7 \%)$ patients had crater defects. Out of 75 females, $16(21.3 \%)$ patients had craters, $3(4 \%)$ had one-wall defects, 4 (5.3\%) had two-wall defects, and 2 (2.7\%) had three-wall defects. They concluded that prevalence and distribution are with multifactorial etiology for bone defects. ${ }^{12}$

Indurkar et al. reported $83.1 \%$ prevalence of bone defects with $57.8 \%$ in males and $42.2 \%$ in females. ${ }^{13}$ Sachdev et al. evaluated the prevalence of bone defects and observed $97 \%$ bone defects among 1010 defects. Among this, majority of the defects were in posterior and in the mandibular area. ${ }^{14}$ Najim and Norderyd observed only
$2.2 \%$ of the prevalence of bone defects from 5898 molar teeth examination. ${ }^{15} \mathrm{Wu}$ et al. found bone defects with 483 teeth out of 1376 examined teeth. They also observed $26.50 \%$ crater type, followed by $23.40 \%$ circumferential, $20.08 \%$ with three-wall defect, and $40 \%$ with complicated defects in Taiwanese patients. ${ }^{16}$

We enrolled 140 patients of both genders age ranged from 18 to 58 years with endo-perio lesions in mandibular molar teeth. In the present study, 78 (55.7\%) cases had two-wall defects and 62 $(44.3 \%)$ cases had three-wall defects. Mitra et al. conducted a study utilizing 20 sites with three-wall defects which were divided equally into 10 sites. Group I patients used T-PRF and group II patients used PRF. Clinical parameters such as probing pocket depth and clinical attachment level were assessed in the beginning, after 3 months, and after 9 months. The authors found a marked reduction in probing pocket depth and a gain in clinical attachment level in both the groups from baseline to 9 months in intragroup comparisons similar to our results. ${ }^{17}$ T-PRF revealed denser fibril meshwork as compared to PRF on both light and scanning electron microscopy.

We found that $32.68 \%$ change was there in probing pocket depth for group I and $33.41 \%$ change in group II after 3 months. We observed a nonsignificant $(p>0.05)$ intergroup dissimilarity, whereas intragroup association demonstrated a considerable distinction $(p<0.05)$. Similarly, in group I, there was $42.59 \%$ change and $43.90 \%$ change after 6 months in group II. Our results are in accordance with the results of Chatterjee et al. and Mitra et al., ${ }^{6,17}$ Chatterjee et al. evaluated three-wall intrabony osseous defects 
using open flap debridement (OFD), autologous PRF, and OFD with T-PRF. They observed no statistically significant difference in the result with PRF and T-PRF groups, which is similar to our results. ${ }^{6}$ After using the T-PRF membrane in rabbit samples, Tunali et al. observed newly forming connective tissue, wound healing, and new bone formation in a 30 day time period. ${ }^{5}$

Shashikumar et al. reported a case of endo-periolesion in mandibular central incisor in a 52-year-old female patient. Phase I therapy, that is, scaling and root planning, was planned and followed by the conventional root canal therapy. The periodontal surgery with the use of PRF was done, and the patient was recalled after 3 months and 6 months. On subsequent visits, radiographs showed a significant reduction in pocket depth and there was a gain of attachment level. The author suggested that PRF is an effective regenerative material, especially in the case of endo-perio lesions. ${ }^{18}$

We found $31.20 \%$ change after 3 months in RAL group I and $31.60 \%$ change in group II. The intergroup distinction was not significant $(p>0.05)$, whereas intragroup evaluation established considerable discrepancy $(p<0.05)$. After 6 months, the mean change was $40.82 \%$ in group I and $42.12 \%$ in group II.

Though there are various advantages of PRF, it has disadvantages also. Since it is autologous, the final amount available is very less. ${ }^{19}$ The success of PRF is altered by the blood collection time and its transference for the centrifuge. There is a requirement of a glasscoated tube for clot polymerization. It carries the risk of dehydration causing shrinkage and alteration in the structural integrity of PRF. ${ }^{20}$

Re-attachment was observed with PRF. Since it is a reservoir of growth factors and cytokines, it promotes periodontal tissue healing and stimulates cell proliferation. ${ }^{17}$ Tunali et al. observed similar histological findings in both PRF and T-PRF, but denser fibrin clot with T-PRF. ${ }^{5}$ T-PRF has an advantage over PRF; it is more biocompatible as it did not contain silica particles, lasts longer in tissue, and produces denser fibrin matrix. ${ }^{5}$ There was no statistically significant difference between the groups due to similar histological findings, bone regeneration, and tissue healing capacity, which is in accordance with Mitra et al., Chatterjee et al., and Tunali et al. 5,6,17 However, T-PRF shows more promising results. The use of PRF has shown to relieve symptoms of pain and swelling. ${ }^{21}$

With the use of PRF and fibrin-PRF, the complex case of endoperio lesions can be efficiently managed. Monga et al. ${ }^{22}$ compared the effectiveness of hydroxyapatite or PRF in a curetted periapical defect in 30 patients in the maxillary anterior region and observed significantly faster healing after 9 months in group III (82.36\%) which utilized PRF in the curetted periapical defect. Moreover, there is an evidence of effective clinical and radiographic bone regeneration with PRF. ${ }^{23-25}$

The limitation of the study is the small sample size. Only PRF and T-PRF were compared. The incorporation of different regenerative agents could have been provided useful and different results.

\section{Conclusion}

Authors suggested that both PRF and fibrin-PRF were effective in inducing a reduction in pocket depth and useful in gaining attachment level.

\section{Ethical Approval}

Obtained

\section{References}

1. Sharma A, Pradeep AR. Treatment of 3-wall intrabony defects in patients with chronic periodontitis with autologous plateletrich fibrin: a randomized controlled clinical trial. J Periodontol 2011;82(12):1705-1712. DOI: 10.1902/jop.2011.110075.

2. Thorat M, Pradeep AR, Pallavi B. Clinical effect of autologous plateletrich fibrin in the treatment of intra-bony defects: a controlled clinical trial. J Clin Periodontol 2011;38(10):925-932. DOI: 10.1111/j.1600051X.2011.01760.x.

3. Aroca S, Keglevich T, Barbieri B, et al. Clinical evaluation of a modified coronally advanced flap alone or in combination with a platelet-rich fibrin membrane for the treatment of adjacent multiple gingival recessions: a 6-month study. J Periodontol 2009;80(2):244-252. DOI: 10.1902/jop.2009.080253.

4. Vishwanath V, Rao HM, Keshava Prasad BS, et al. Successful endodontic management of endo-perio lesions with different treatment modalities: case series. SRM J Res Dent Sci 2019;10(2):105109. DOI: 10.4103/srmjrds.srmjrds_16_19.

5. Tunalı M, Özdemir H, Küçükodacı Z, et al. In vivo evaluation of titanium-prepared platelet-rich fibrin (T-PRF): a new platelet concentrate. Br J Oral Maxillofac Surg 2012;51(5):438-443. DOI: 10.1016/j.bjoms.2012.08.003.

6. Chatterjee A, Pradeep AR, Garg V, et al. Treatment of periodontal intrabony defects using autologous platelet-rich fibrin and titanium platelet rich fibrin: a randomized, clinical, comparative study. J Investig Clint Dent 2017;8:e12231. DOI: 10.1111/jicd.12231.

7. Eren G, Tervahartiala T, Sorsa T, et al. Cytokine (interleukin-1beta) and MMP levels in gingival crevicular fluid after use of platelet-rich fibrin or connective tissue graft in the treatment of localized gingival recessions. J Periodontal Res 2016;51:481-488. DOI: 10.1111/jre.12325.

8. Dohan Ehrenfest DM, Del Corso M, Diss A, et al. Three-dimensional architecture and cell composition of a Choukroun's platelet-rich fibrin clot and membrane. J Periodontol 2010;81:546-555. DOI: 10.1902/ jop.2009.090531.

9. Dambhare A, Bhongade ML, Dhadse PV, et al. A randomized controlled clinical study of autologous platelet rich fibrin (PRF) in combination with HA and beta-TCP or HA and beta-TCP alone for treatment of furcation defects. J Hard Tissue Biol 2019;28(2):185-190. DOI: 10.2485/jhtb.28.185.

10. Goyal L, Gupta N, Gupta ND. Autologous platelet-rich derivatives along with alloplastic bone substitute in the management of complex perio-endo cases. J Indian Soc Periodontol 2020;24(2):182-185. DOI: 10.4103/jisp.jisp_81_19.

11. Patel GK, Deepika PC, Sisodia N, et al. Platelet rich fibrin in management of complex endoperio cases. Kathmandu Univ Med J (KUMJ) 2017;15(57):102-105.

12. Singh PK, Kumari A. Prevalence and distribution of different types of bone defects in chronic periodontitis in Bagalkot subjects: a clinical study. Int J Sci Stud 2017;5(3):284-289.

13. Indurkar MS, Verma R. Evaluation of the prevalence and distribution of bone defects associated with chronic periodontitis using conebeam computed tomography: a radiographic study. J Interdiscip Dent 2016;6(3):104-109. DOI: 10.4103/2229-5194.201647.

14. Sachdeva S, Phadnaik MB, Mania A, et al. Prevalence and distribution of bone defects associated with moderate and severe periodontitis patients. Clinical Epidemiology and Global Health 2020; 1-6. [In press].

15. Najim U, Norderyd O. Prevalence of intrabony defects in a swedish adult population. A radiographic epidemiological study. Acta Odontologica Scandinavica 2017;17(2):123-129. DOI: 10.1080/00016357.2016.1265665.

16. Wu SK, Yeh HC, Chan CP. The prevalence and distribution of bone defects in patients with moderate to advanced periodontitis. Chang Gung Med J 2001;24(7):423-430. 
17. Mitra DK, Potdar PN, Prithyani SS, et al. Comparative study using autologous platelet-rich fibrin and titanium prepared platelet-rich fibrin in the treatment of infrabony defects: an in vitro and in vivo study. J Indian Soc Periodontol 2019;23(6):554-561. DOI: 10.4103/ jisp.jisp_562_18.

18. Shashikumar P, Nisha S. Autologous platelet concentrate as a potential regenerative biomaterial in the treatment of endo-perio lesion. Indian J Oral Health Res 2016;2:106-109. DOI: 10.4103/23938692.196148.

19. Yu-Chao C, Kuo-Chin W, Jiing-Huei Z. Clinical application of platelet-rich fibrin as the sole grafting material in periodontal intrabony defects. J Dent Sci 2011;6:181-188. DOI: 10.1016/j.jds.2011. 05.010 .

20. Maniyar N, Sarode GS, Sarode SC, et al. Platelet-rich fibrin: a "wonder material" in advanced surgical dentistry. Med J DY Patil Vidyapeeth 2018;11:287-290. DOI: 10.4103/MJDRDYPU.MJDRDYPU_204_17.

21. Del Fabbro M, Ceresoli V, Lolato A, et al. Effect of platelet concentrate on quality of life after periradicular surgery: a randomized clinical study. J Endod 2012;38(6):733-739. DOI: 10.1016/j.joen.2012. 02.022.

22. Monga P, Grover R, Mahajan P, et al. A comparative clinical study to evaluate the healing of large periapical lesions using platelet-rich fibrin and hydroxyapatite. Endodontology 2016;28:27-31. DOI: 10.4103/0970-7212.184336.

23. Jayalakshmi KB, Agarwal S, Singh MP, et al. Platelet-rich fibrin with $\beta$-tricalcium phosphate-a novel approach for bone augmentation in chronic periapical lesion: a case report. Case Rep Dent 2012;2012:902858. DOI: 10.1155/2012/902858.

24. Thanikasalam M, Ahamed S, Narayana SS, et al. Evaluation of healing after periapical surgery using platelet-rich fibrin and nanocrystalline hydroxyapatite with collagen in combination with platelet-rich fibrin. Endodontology 2018;30:25-31.

25. Deenadayalan E, Kumar A, Tewari RK, et al. Management of large periapical lesion with the combination of second generation platelet extract and hydroxyapatite bone graft: a report of three cases. J Clin Diagn Res 2015;9(1):ZD24-ZD27.DOI: 10.7860/JCDR/2015/10885.5482. 